\title{
Life Perspective and Social Health after Acid Burn: An Observational Study of Three Victims
}

Unsa Athar ${ }^{1,2}$, Saad Ur Rahman ${ }^{3}$, Seemab Imtiaz Gill ${ }^{3}$, Taimoor Jamil ${ }^{3}$, Muhammad Awais Sharif ${ }^{3}$, Muhammad Khawar Sana ${ }^{3}$

1. Community Medicine and Public Health, Shalamar Medical and Dental College, Lahore, PAK 2. Community Medicine, King Edward Medical University, Lahore, PAK 3. Internal Medicine, King Edward Medical University, Lahore, PAK

Corresponding author: Unsa Athar, unsa.athar10@gmail.com

\begin{abstract}
After an acid attack, also known as vitriolage, many patients suffer from changes in life perspective, behavior, feelings, social withdrawal, social isolation, and depression. Formal and informal social support is vital for the proper and complete rehabilitation of acid burn victims. The government should form separate public help centers for such patients. The need of the hour, however, is the invention of proper legislation for the prevention of this heinous crime.
\end{abstract}

Categories: Psychology, Public Health, Trauma

Keywords: acid attack victims, vitriolage, social life, life perspective, trauma

\section{Introduction}

Social scientists all over the world are focusing on violence against women in developing and developed countries [1]. The majority of acid burns occur in developing countries where the ability to treat and provide for this population is severely limited due to limited resources for surgery and rehabilitation [2]. Violence against women was defined in the United Nations (UN) Declaration on the Elimination of Violence Against Women. The definition, adopted by the General Assembly in 1993, has described violence against women as; "any act of gender-based violence that results in, or is likely to result in, physical, sexual, or psychological harm or suffering to women, including threats of such acts, coercion or arbitrary deprivation of liberty, whether occurring in public or private life" [3]. Acid throwing, or vitriolage, is being considered a worthdiscussing concern in Pakistan nowadays [4].

According to a research done in Bangladesh, acid is used as a common tool for violence because it is cheap and easily accessible [5]. Research from Cambodia showed that acid throwing does not have medical effects only, it damages the psychological, social, and economic aspects of a victim's life as well [6].

Received 07/20/2020 Review began 07/21/2020 Review ended 07/21/2020 Published 08/04/2020

\section{() Copyright 2020}

Athar et al. This is an open access article distributed under the terms of the Creative Commons Attribution License CC-BY 4.0., which permits unrestricted use, distribution, and reproduction in any medium, provided the original author and source are credited.
Our study aimed to find out about the change in life perspective of acid burn victims after the incident and evaluate the effects on their personal and social life. We planned to investigate the following: (a) consequences of acid burn violence on women's social health, (b) identify and understand the context associated with life perspective and feelings of an acid burn victim, and (c) identify the formal and informal support offered to an acid burn victim. Our study will help to formulate ethical and legislative rules and regulations to rehabilitate acid burn victims and to prevent such accidents from happening.

\section{Materials And Methods}

This is an observational study of three cases. Particpant \#1 is A, an unmarried woman and participant \#2 is $\mathrm{B}$, her young sister, who suffered acid burn violence. Particpant \#3 is C, a married factory worker from the urban slums of Lahore. All of them are of poor socio-economic status residing in an urban area. The victims were identified from the records of acid burn patients presenting to Mayo hospitals, Lahore, Pakistan in past years. They were called to follow-up their case. The respondents were assured of the confidentiality and informed consent was obtained but the use of audiotape machines, cellular phones, and taking photographs was not allowed. However, the research assistant was allowed to take notes.

Two sessions were held with each participant. The first was to develop the rapport while the second was an in-depth interview. Data were collected using a question guide.

The research assistant took notes of the interview, which were later tallied with the observations. The second interview was conducted to fill out the gaps in the previous one. The content analysis is done by appropriate consistent coding.

\section{Results}

The victim, A, aged 20 years can speak two languages Urdu and Punjabi. She is an illiterate woman who lived 
with her parents, with her two elder brothers and one younger sister. Her sister is victim \#2, B. Her sister and she both experienced acid burn, and psychological harassment as a result. The acid was thrown on her face and neck by her neighbor in the middle of the night. Her sister, B, aged 6, was sleeping next to her, who also suffered an acid burn on her right arm and chest. The neighbor was a male, who threw acid on her face after she turned down the proposal from him. She had partial blindness, partial deafness, and severe disfigurement. The victim suffered from psychological assault from the relatives and neighbors after the incident, which led to their family moving to another neighborhood. The younger girl has no permanent scarring but is psychologically traumatized.

The third victim, C, is a married, 30-year-old lady who used to work at a factory in an urban slum. She has two children. She got in an argument with the factory manager over the delay in dispersing salaries. She threatened to file an official complaint in the police. The next day, the manager threw acid on her face and said it was an accident. She was fired from her job. C feels socially isolated and depressed. Her husband is unemployed and blames her for losing her job. She feeds her children with help from her parents, who also brought her to the Mayo Hospital for treatment and management.

\section{Theme \#1 - life perspective, behavior, and feelings}

The main theme that came up after the interview was a change in the women's perspective about life. The younger girl did not understand fully the concept of life and behavior but seemed less talkative and cheerful than a child of her age should be. The elder sister was doing all the talking for her sister as well.

The major theme of life perspective can be described into three sub-themes; depression/inferiority complex, anger, and hope (Table 1).

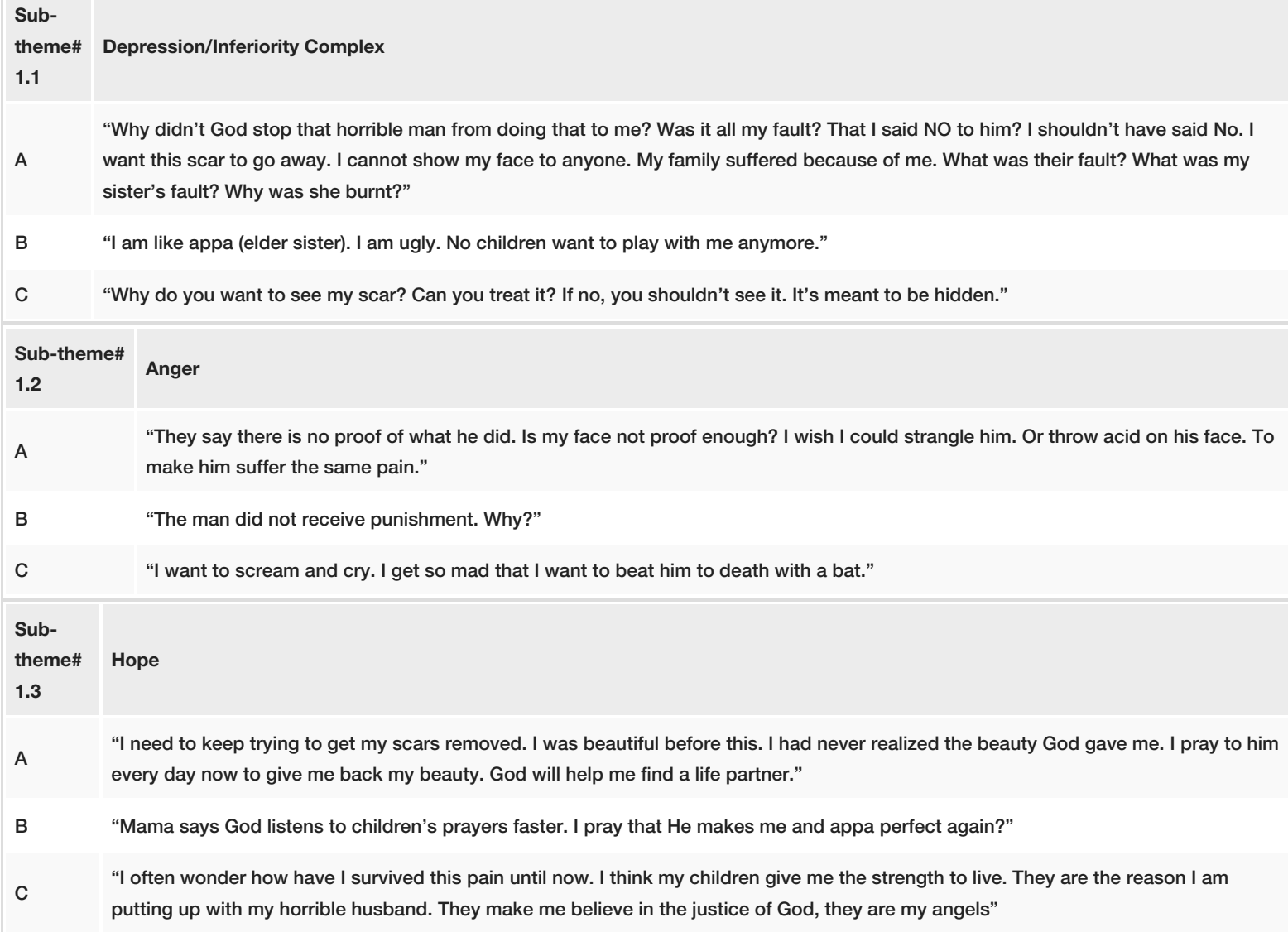

B "Mama says God listens to children's prayers faster. I pray that He makes me and appa perfect again?"

C "I often wonder how have I survived this pain until now. I think my children give me the strength to live. They are the reason I am putting up with my horrible husband. They make me believe in the justice of God, they are my angels"

TABLE 1: Theme \#1 - life perspective, behavior, and feelings

\section{Theme \#2 - social stigmatization and social withdrawal}

The victims suffered from social stigmatization and social withdrawal because of the permanent scarring of their faces and bodies. There was a feeling of self-blame which led to further social isolation. Seeing the pity or disgust in people's eyes made the victims recoil which led to limited social interactions. Constant victim shaming and body shaming also contributed towards the social withdrawal. Victim shaming and social 


\section{Cureus}

isolation were the two sub themes seen, as described in Table 2.

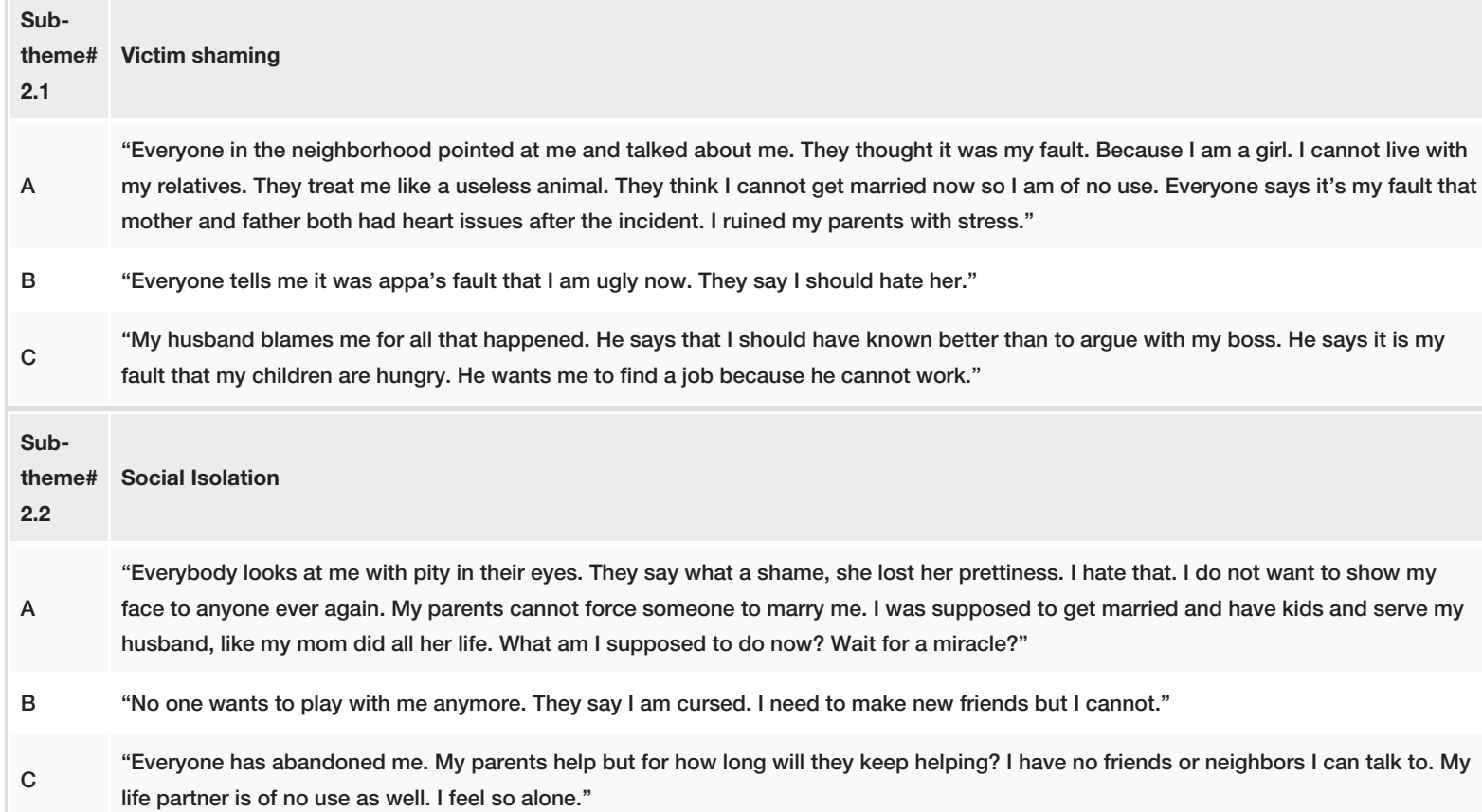

TABLE 2: Theme \#2 - social stigmatization and social withdrawal

\section{Theme \#3 - social support}

Formal

The public sector hospitals (Gujranwala Hospital and Mayo Hospital) funded by the government were involved in management and rehabilitation after abuse. The victims underwent many reconstructive surgeries. They did try to contact non-government organizations but it was hard to find one without contacts. The caregivers helped them to the best of their abilities regarding their health problems and physical disabilities, but could not play a substantial role in their rehabilitation. The formal social support must be empowered and funded to rehabilitate acid burn victims (Table 3).

Informal

The victim received strong informal social support. Their parents, children, and siblings provided informal social support like emotional, moral, and financial support without any pre-defined criteria or policies. Their families took them to hospitals to get the surgeries done. The victims seemed grateful and indebted to the family for all the informal support they provided (Table 3). 


\section{Cureus}

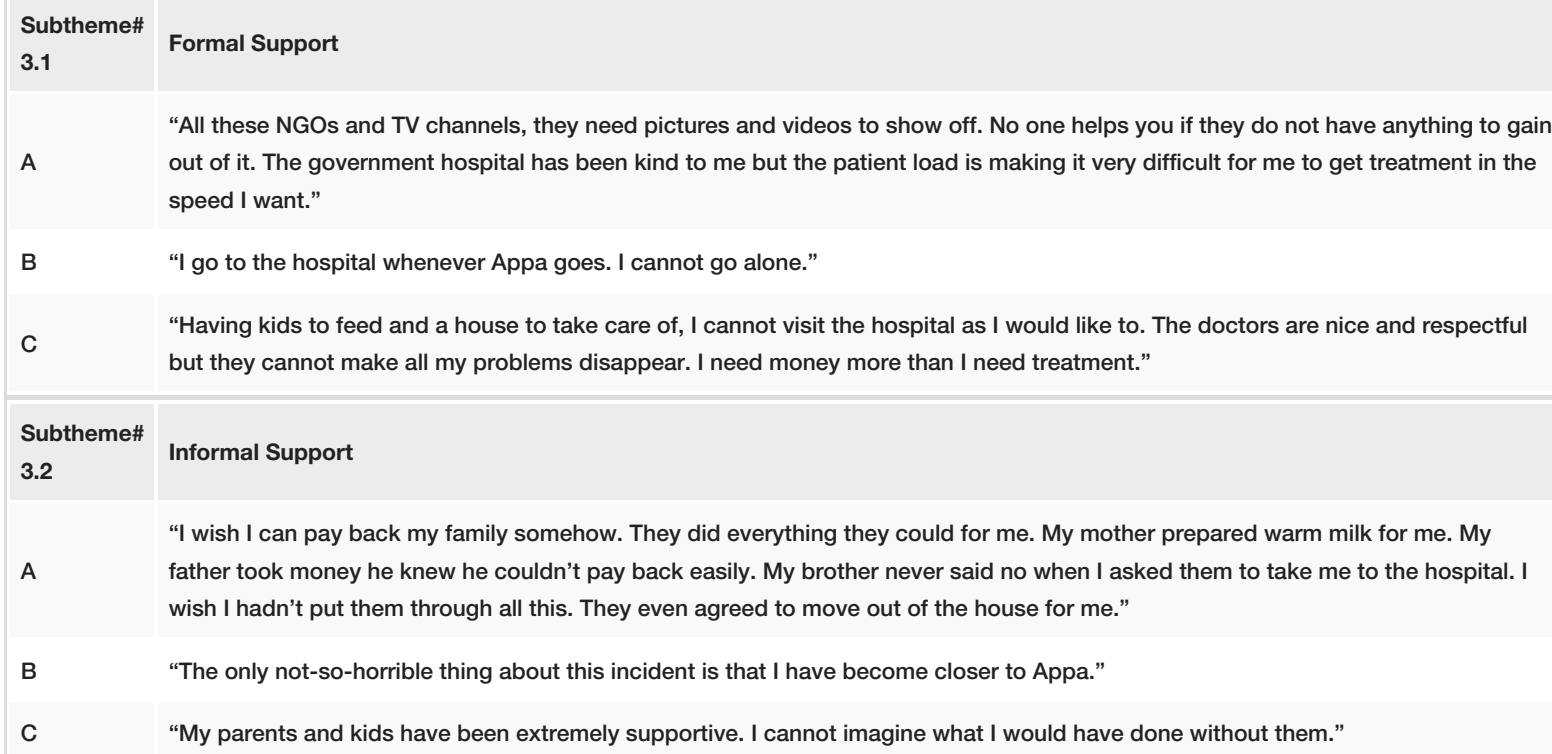

TABLE 3: Theme \#3 - social support

\section{Discussion}

The article explores the facts and figures related to acid burn attacks on the women and various factors associated with it. The number of acid burn victims is increasing in countries where rehabilitation services are the lowest [2]. These are the highest in Southeast Asia including countries like Bangladesh, Pakistan, India, China, Malaysia, Nigeria, Cambodia, and Uganda [7]. In Pakistan, these numbers are alarmingly high [1] and are considered now a topic worth discussion and research [4]. In Punjab, 48 out of 52 (92\%) cases of violence against women were acid burn victims. This rate is alarmingly high, in comparison to Sindh where the rate is $3 \%$. This shows that acid throwing is an issue of majorly populated areas, as depicted by our case study [3]. The reason for these high numbers is the easy and cheap availability of acids [5]. Acid violence against women is influenced by many factors like age, sex, ethnicity, social status, etc [7].

Data from Pakistan, particularly Punjab [8] suggests that psychological violence is much more than physical violence in Pakistan. One of the reasons behind this is the use of illegal arbitration systems like 'panchaits' (an illegal congregation of leaders and influential elders belonging to a rural area which decide punishments on matters of their area). Women fear going to the police or courts due to the concept of humiliation. And even when they contact the law, there is no legislation or proper policies to provide justice to acid burn victims. Our case indicates the same. The criminal was freed from jail because of the lack of proper laws.

Several factors have been associated with this acid throwing including the feeling of revenge, dowry issues, refusal of marriage issues, quarrels over land, and property [9]. In some cases, women's higher financial status as compared to their spouse was associated with high rates of violence, specifically in post-Soviet countries [10]. Another factor linked to female violence was the concept of "wife-beating". This culture is quite common in African and middle-east countries [11].

A study by García-Moreno emphasized the fact that the women who fall prey to partner violence also suffer from higher rates of different health-related issues and risk behavior including reproductive health problems, mental health problems, and deaths due to homicide or suicide [12]. A study conducted in Bangladesh states that acid violence often also affects small children sleeping beside the actual victim [7], which is similar to our case study. The same research states that acid burns can lead to social withdrawal and isolation, also seen in our study. Our case study poses similarities with a Cambodian case series that shows that acid burns have devastated and long-term medical effects, along with emotional deterioration [6]. Another research analyzed the emotional and social effects of acid burns according to Derriford and Rosenberg scales, and indicated depression due to physical appearance and low self-esteem [13]. Our victims also showed signs of depression and low self-esteem. A study shows that patients who experience physical or sexual assault such as acid throwing can suffer from post-traumatic stress disorder (PTSD). The symptoms of PTSD include nervousness, irritability, and the fear that the event might occur again [14]. Our patients showed all these signs.

A study by Patel states that a lot of formal and informal support is needed to rehabilitate acid burn victims [15]. Our victims had informal social support, but the lack of formal social is preventing them from proper 
rehabilitation. The same research also shows that social and cultural attitude towards acid burn victims is different in the eastern societies, leading to appearance-related distress. A study by Milton [16] also poses similarities to ours by stating that most victims are young females, who suffer from acid throwing by a dominant male, after refusing his proposal. Also, permanent facial scarring leads to social stigmatization. The social withdrawal and feeling of helplessness in our patients were aggravated by the lack of substantial laws to punish the wrong-doers. This is similar to Bangladeshi and Cambodian [17] cases, where the absence of legislation for acid burn victims is problematic for the patients.

Social support is defined as the practical, emotional, and moral support provided to patients in formal and informal ways [18]. Low levels of social support have been found to have a qualitative relationship with posttraumatic stress disorder. Moreover, it has been reported that social support, both parental support and family conflict, can help in recovering from the traumatic incidents [19]. Social support helps in mental wellbeing as well as physical well-being because support increases levels of interleukin-1 that helps in wound healing [20]. Our patients depict similar findings. Informal social support has helped the patients recover and develop positive feelings, while more formal support is needed to enhance their healing process. Moreover, several gender training and equity programs are introduced which have resulted in the reduction of violence to $55 \%$ clearly showing positive results [21-22].

From the above discussion, we can say that researches from other countries share similarities with our case study. Many patients suffer from changes in life perspective, behavior, feelings, social withdrawal, social isolation, and depression. Formal and informal social support is vital for the proper and complete rehabilitation of acid burn victims. Many non-government organizations (NGOs) are working at the moment, but our public hospitals should be equipped with proper tools and services for rehabilitation. Moreover, to help with the recovery of patients and to prevent such accidents in the future, the government needs to formulate solid policies and rules. Enforcement of law and justice will work wonders in such situations. But data from Pakistan is not sufficient and more research is needed to convince the authorities to take proper action.

\section{Limitations}

Our study is limited by convenient sampling and a small sample size. Convenient sampling was adopted due to the lack of resources. The small sample size occurred largely due to the unwillingness of selected subjects to talk about the incident of vitriolage as it entailed an unpleasant recalling of their trauma.

\section{Recommendations}

We recommend the following steps to be taken, based on our experience while conducting this study:

1. Every government hospital, specially the tertiary ones, must have a separate, public rehabilitative center for patients who experienced vitriolage. These centers must work under the departments of plastic and reconstructive surgery. The management should be multi-disciplinary, with involvement of the departments of psychiatry/psychology. Every patient presenting to the hospital for initial

evaluation/reconstruction/rehabilitation after an acid attack must be evaluated by a psychiatrist as well. This will ensure $\mathrm{h}$ improved quality of life, following trauma.

2. Hospitals dealing with acid burn patients must work with NGOs for providing social support. Formation of support groups should be encouraged, where victims of vitriolage meet to share and discuss the trauma they experienced. Departments dealing with such patients must have referral information for these support groups.

3. Multiple attempts have been made by the government to prevent acid and burn attacks. Punishments for such heinous crimes have also been decided. But all this legislation is on paper. Strict implementation of legislation via transparent work by police and judiciary is needed. Perpetrators of vitriolage must be tracked down and brought to justice on priority basis.

\section{Conclusions}

Three patients suffering from vitriolage were studied in two sessions to analyze the change in life perspective after the incident and its effect on their social health. In conclusion, it can be said that the criminal act of acid-throwing causes physical damage as well as psychological damage. Surgery and medicine can deal with the scarring and the physical sequelae but complete rehabilitation must involve psychiatric and psychological therapy as well. The government should form separate public help centers for such patients. The need of the hour, however, is the invention and implementation of proper legislation for the prevention of this heinous crime.

\section{Additional Information \\ Disclosures}


Human subjects: Consent was obtained by all participants in this study. Animal subjects: All authors have confirmed that this study did not involve animal subjects or tissue. Conflicts of interest: In compliance with the ICMJE uniform disclosure form, all authors declare the following: Payment/services info: All authors have declared that no financial support was received from any organization for the submitted work. Financial relationships: All authors have declared that they have no financial relationships at present or within the previous three years with any organizations that might have an interest in the submitted work. Other relationships: All authors have declared that there are no other relationships or activities that could appear to have influenced the submitted work.

\section{Acknowledgements}

The authors would like thank the following people for their help in data collection: Dr. Ayesha Irfan, Dr. Hassan Saeed, Dr. Hafeez-ur-Rahman, Dr. Shaarif Kaleem and Dr. Waqar Ahmed. They also helped in working on the initial version of this article, which is available as an un-reviewed pre-print here: https://preprints.jmir.org/preprint/12021. DOI: 10.2196/preprints.12021. We would also like to thank Dr. Saira Afzal for helping with the conception of the idea and Dr. Mustehsan Bashir for helping out with the retrieval of data.

\section{References}

1. Van Hightower NR, Gorton J: A case study of community-based responses to rural woman battering Violence Against Women. 2002, 8:845-72. 10.1177/107780102400388506

2. Asaria J, Kobusingye OC, Khingi B, Balikuddembe R, Gomez M, Beveridge M: Acid burns from personal assault in Uganda. Burns. 2004, 30:78-81. 10.1016/j.burns.2003.08.009

3. Farid S, Sajid IA, Ali N: Violence against women in Pakistan: constraints in data collection . Pak J Criminol. 2010, 2:93-110.

4. Akhter GA, Islam F: Acid violence: a burning issue in Bangladesh . Ibrahim Med Coll J. 2014, 7:12-5. 10.3329/imci.v7i1.17744

5. Breaking the silence: addressing acid attacks in Cambodia . (2010). Accessed: July 10, 2020: http://2010https://cchrcambodia.org/admin/media/report/report/english/2010-05-21\%20Breaking\%20the\%20Silence\%20Addres....

6. Rahman M, Bhuiyan FA, Lovely FH: Acid violence: a burning impact on women of Bangladesh-case study . Int J Adv Res Eng Appl Sci. 2014, 3:40-57.

7. von Werlhof E: Scarred for life: the impact of the Acid Control and Acid Crime Prevention Act of 2010 on addressing violence against women in Pakistan. Int Rev Law. 2014, 3:1-11.

8. Manzoor R, Abdul Rahman A, Bano M: Violence against women in Pakistan: evidence from Punjab . Int J Adv Res. 2013, 1:356-65.

9. Faga A, Scevola D, Mezzetti M, Scevola S: Sulphuric acid burned women in Bangladesh: a social and medical problem. Burns. 2000, 26:701-9.

10. Ismayilova L: Spousal violence in 5 transitional countries: a population-based multilevel analysis of individual and contextual factors. Am J Public Health. 2015, 105:e12-e22. 10.2105/AJPH.2015.302779

11. Wang L: Factors influencing attitude toward intimate partner violence . Aggress Violent Behav. 2016, 29:728.

12. García-Moreno C, Pallitto C, Devries K, Stöckl H, Watts C, Abrahams N: Global and regional estimates of violence against women: prevalence and health effects of intimate partner violence and non-partner sexual violence. WHO. 2013, 1-58.

13. Kalantry S, Getgen Kestenbaum J: Combating acid violence in Bangladesh, India and Cambodia. Cornell Legal Studies Research Paper. 2011,

14. Asalgoo S, Jahromi G, Meftahi G, Sahraei H: Posttraumatic stress disorder (PTSD): mechanisms and possible treatments. J Neurophysiol. 2015, 47:482-9.

15. Patel AB, Patel B, Patel BV: Health care management of acid attack survivors: a review . Int J Med Pharm Res. 2016, 4:231-236.

16. Milton R, Mathieu L, Hall AH, Maibach HI: Chemical assault and skin/eye burns: two representative cases, report from the Acid Survivors Foundation, and literature review. Burns. 2010, 36:924-32. 10.1016/j.burns.2009.10.020

17. Gollogly JG, Vath SB, Malmberg A: Acid attacks in Cambodia: serious reminders of personal conflicts . Asian Biomed. 2008, 2:329-34.

18. Noronha DO, Faust J: Identifying the variables impacting post-burn psychological adjustment: a metaanalysis. J Pediatr Psychol. 2007, 32:380-91. 10.1093/jpepsy/jsl014

19. Trauma symptoms in sexually abused children: risk and protective factors . (2004). Accessed: July 2, 2020: https://nsuworks.nova.edu/cps facpresentations/1979/.

20. Mehnert A, Lehmann C, Graefen M, Huland H, Koch U: Depression, anxiety, post-traumatic stress disorder and health-related quality of life and its association with social support in ambulatory prostate cancer patients. Eur J Cancer Care. 2010, 19:736-45. 10.1111/j.1365-2354.2009.01117.x

21. Pronyk PM, Hargreaves JR, Kim JC, et al.: Effect of a structural intervention for the prevention of intimatepartner violence and HIV in rural South Africa: a cluster randomised trial. Lancet. 2006, 368:1973-83. 10.1016/S0140-6736(06)69744-4

22. Vyas S, Heise L: How do area-level socioeconomic status and gender norms affect partner violence against women? Evidence from Tanzania. Int J Public Health. 2016, 61:971-80. 